\title{
Percepção e pesquisa na paisagem sonora: os fluxos do meio e o observador participante
}

\author{
HENRIQUE GOMES
}




\section{RESUMO}

Apresento nesse artigo uma breve discussão acerca do conceito de paisagem sonora, originalmente introduzido por R. Murray Schafer, sobretudo na abordagem de Tim Ingold em seu artigo intitulado Against Soundscape e do trabalho de pesquisa performativa de Annette Arlander, mais especificamente durante o período de Animal Years, de forma a buscar pistas de como se aproximar do som na pesquisa em artes. R. Murray Schafer foca, em sua reflexão e prática no contexto do World Soundscape Project, no aprimoramento da escuta como forma de desenvolver a discussão em torno da ecologia acústica e da poluição sonora. Além de levar em consideração aspectos ambientais e sociológicos do lugar como fatores pertinentes ao som, como sugere a análise histórica de Emily Thompson, busco também pensar como a experiência perceptiva se dá na cooperação dos sentidos imersos no espaço. Para Ingold, não há uma relação entre observador passivo que percebe a realidade concreta e pondera sobre os aspectos de determinado conjunto de sons. Há um processo dinâmico e recíproco entre o ambiente e um observador que é, necessariamente, participativo. Dessa forma, a pesquisa do som de um lugar é indissociável de aspectos visuais, táteis, ambientais e sociológicos da paisagem e da presença desse corpo participante.

PALAVRAS-CAVE

Paisagem sonora, percepção, pesquisa em artes, tempo.

\section{ABSTRACT}

In this paper I present a brief discussion on the concept of soundscape, originally introduced by R. Murray Schafer, especially in the approach of Tim Ingold in his article entitled Against Soundscape, and the work of Annette Arlander on performative research, specifically during the period of Animal Years, in order to search for clues of how to approach sound in art research. R. Murray Schafer focuses, in his reflection and practice in the context of the World Soundscape Project, in the improvement of listening as a way to develop the discussion around acoustic ecology and noise pollution. In addition to taking into account environmental and sociological aspects of the place as factors pertinent to sound, as the historical analysis of Emily Thompson suggests, I think about how the perceptive experience takes place in the cooperation of the senses immersed in space. For Ingold, there isn't a relation between a passive observer who perceives the concrete reality and ponders on aspects of a particular set of sounds. There is a dynamic and reciprocal process between the environment and an observer who is necessarily participatory. In this way, the sound research of a place is inseparable from visual, tactile, environmental and sociological aspects of the landscape and the presence of this participant body.

\section{KEYWORDS}

Soundscape, perception, art research, weather. 


\section{A paisagem sonora e os fluxos do meio}

O World Soundscape Project (WSP) é um grupo de pesquisa que surge no final dos anos 60 na Simon Fraser University, em uma tentativa de R. Murray Schafer de chamar atenção para as rápidas mudanças no ambiente sonoro na cidade de Vancouver. O grupo utiliza-se do conceito de paisagem sonora (soundscape) já em seu primeiro projeto, um estudo detalhado da paisagem sonora de Vancouver em 1972, The Vancouver Soundscape. Um dos integrantes do projeto, Barry Truax, define soundscape como:

Um ambiente de som (ou ambiente sônico) com ênfase na forma como o som é percebido e entendido pelo indivíduo, ou por uma sociedade. Também depende da relação entre o indivíduo e um ambiente dado qualquer. $O$ termo pode se referir a ambientes reais, ou a construções abstratas como composições musicais e colagens sonoras, particularmente quando considerado como um ambiente artificial. (TRUAX, 1978, tradução minha) ${ }^{1}$

R. Murray Schafer demonstra sua preocupação com as mudanças no ambiente acústico mundial ao mesmo tempo em que procura chamar a atenção para a percepção do som que, segundo ele, teria sido negligenciada em relação a visão. Schafer explica que a poluição sonora estava sendo tratada através do foco na diminuição de ruídos, uma abordagem negativa. Segundo Schafer, "precisamos procurar uma maneira de tornar a acústica ambiental um programa de estudos positivo. Que sons queremos preservar, encorajar, multiplicar? (..) Para revelá-los, pode ser necessário investir contra os que não são importantes" (SCHAFER, 1977). Sendo assim, o entendimento da paisagem sonora envolve um processo de escuta ativa, consciente do fenômeno sonoro em si. Pierre Schaeffer, em seu Tratado dos objetos musicais, define quatro escutas distintas: escutar, ouvir, entender e compreender. Ouvir diferencia-se de escutar por tratar-se de uma escuta ativa, onde o indivíduo direciona a escuta a determinado som. Ao examinar os dados obtidos por essa escuta ativa, o indivíduo pode entender ${ }^{2}$ como as características desse som se manifestam, tomando consciência do fenômeno sonoro. A compreensão de determinado objeto sonoro surge da relação semântica do som em determinada linguagem, quando o som é tratado como signo. Para Schaeffer, toda a relação com o objeto sonoro estrutura-se na oposição entre sujeito receptivo e realidade concreta, visto que a escuta ocorre em um processo subjetivo em relação a um dado concreto. Essa relação entre sujeito e realidade mostra-se pertinente ao pensar um processo onde o indivíduo, ao escutar ativamente, tem maior consciência sonora do espaço em que vive e pode contribuir para a preservação e valorização de determinados sons, visando confrontar a poluição sonora que preocupa R. Murray Schafer

\footnotetext{
${ }^{1}$ No original: "An environment of sound (or sonic environment) with emphasis on the way it is perceived and understood by the individual, or by a society. It thus depends on the relationship between the individual and any such environment. The term may refer to actual environments, or to abstract constructions such as musical compositions and tape montages, particularly when considered as an artificial environment."

2 No original: "An environment of sound (or sonic environment) with emphasis on the way it is perceived and understood by the individual, or by a society. It thus depends on the relationship between the individual and any such environment. The term may refer to actual environments, or to abstract constructions such as musical compositions and tape montages, particularly when considered as an artificial environment."
} 
e o WSP. Nesse contexto, "somente uma total apreciação do ambiente acústico pode nos dar recursos para aperfeiçoar a orquestração da paisagem sonora mundial" (SCHAFER, 1977). Apesar da pertinência da reflexão de Schafer, outras questões surgiram acerca da paisagem sonora e da sua relação com as cidades. Emily Thompson, ao analisar o impacto do surgimento do que ela chama de sons da modernidade nos Estados Unidos, entre os anos 1900 e 1933, traz outra abordagem ao conceito de paisagem sonora apresentado por Schafer:

\begin{abstract}
Apesar do trabalho de Schafer continuar socialmente e intelectualmente relevante hoje, as questões que o influenciaram não são as mesmas que motivaram o meu próprio estudo histórico, e eu uso a ideia de paisagem sonora um pouco diferente. Aqui, seguindo o trabalho de Alain Corbin, eu defino a paisagem sonora como uma paisagem auditiva ou auricular. Como uma paisagem (landscape), a paisagem sonora (soundscape) é simultaneamente um ambiente físico e uma forma de perceber o ambiente; é ao mesmo tempo um mundo e uma cultura construída para dar sentido a esse mundo. (...) Uma paisagem sonora, como uma paisagem, em última análise, tem mais a ver com civilização com que natureza, e como tal está constantemente em construção e sempre passando por mudanças. (THOMPSON, 2002, tradução minha) ${ }^{3}$
\end{abstract}

Thompson chama a atenção para o fato de que a paisagem sonora tanto diz respeito ao lugar, quanto a forma de percebê-lo. Isso implica em questionar a relação sujeito e realidade, onde o corpo percebe as ondas sonoras emitidas por diferentes objetos, e pensa a paisagem sonora além do entendimento de características físicas do fenômeno sonoro ou da compreensão de seu caráter de signo. Thompson, como historiadora, está preocupada em analisar as relações sociais e culturais do som na "Era das Máquinas" (Machine Age). Para ela, o surgimento de novos sons evidencia as mudanças na sociedade e implica alterações na percepção dos indivíduos. As mudanças na natureza do som são acompanhadas por mudanças na forma de ouvir e, através da análise dessa cultura do ouvir, é possível tomar consciência das constantes mudanças na sociedade. Em sua empreitada contra a poluição sonora, Schafer faz a distinção entre hi-fi e lo-fi soundscapes. A primeira permite a distinção clara entre os sons devido à ausência de ruídos de fundo, enquanto a segunda é constituída por uma grande quantidade de fenômenos sonoros que se sobrepõe e a perspectiva sonora se perde em meio a variedade de ruídos. Para Schafer, é importante que se construa uma sociedade que preze por hifi soundscapes enquanto Thompson está mais interessada em analisar a sociedade que se desenvolve em meio a esses novos ruídos e percepções sonoras.

\footnotetext{
${ }^{3}$ No original: "While Schafer's work remains socially and intellectually relevant today, the issues that influenced it are not what has motivated my own historical study, and I use the idea of a soundscape somewhat differently. Here, following the work of Alain Corbin, I define the soundscape as an auditory or aural landscape. Like a landscape, a soundscape is simultaneously a physical environment and a way of perceiving that environment; it is both a world and a culture constructed to make sense of that world. (...) A soundscape, like a landscape, ultimately has more to do with civilization than with nature, and as such, it is constantly under construction and always undergoing change"
} 
O esforço aqui volta-se para a reflexão sobre o surgimento desse novo ambiente (environment) e a forma de percebê-lo, destacando que a inserção de novas máquinas e modos de produção são parte efetiva da sociedade que se desenvolve a partir de 1900 , em vez de se concentrar na proposta de uma paisagem sonora ideal.

Schafer enfatiza o caráter hi-fi da natureza, da área rural, enquanto a paisagem sonora moderna, urbana, é caracterizada por certa massa sonora lo-fi que elimina a perspectiva e a distinção entre os sons. Ao polarizar a percepção da paisagem sonora em dois grupos distintos, hi-fi e lo-fi, e relacioná-los diretamente ao rural e ao urbano, Schafer propõe certas características do som da natureza como modelo (o canto intervalado dos pássaros em oposição ao som contínuo do zumbido elétrico ${ }^{4}$ ) para o desenvolvimento de um projeto acústico para as cidades, visando combater a poluição sonora. Dessa forma, a relação entre sujeito receptivo e realidade concreta, presente em seu conceito de paisagem sonora, é reforçada por Schafer. Quando Thompson define a paisagem sonora como uma paisagem auditiva ou auricular, também deixa evidente que a paisagem sonora é uma questão de civilização e intervenção humana acima de qualquer possível natureza do som e, assim como a sociedade, está em um processo de constante mudança. A própria ideia de natureza está em constante transformação visto que é culturalmente produzida. Para Annette Arlander:

O sonho de um "lugar selvagem e curativo" como salvação é tão culturalmente produzida quanto qualquer jardim dos sonhos. $E$ até aquelas áreas que pensamos que estão livres e intocadas pela cultura estão na verdade, em uma análise mais próxima, sendo criadas, suportadas ou protegidas por ela. O lugar selvagem não nomeia ou demarca a si mesmo. O caráter sagrado da natureza é do homem. (ARLANDER, 2003, tradução minha) ${ }^{5}$

Arlander, assim como Thompson, chama a atenção para a relação entre natureza e percepção humana e a impossibilidade de separação entre eles:

Mesmo que tenham nos ensinado que natureza e percepção humana são de dois mundos diferentes eles são, todavia, inseparáveis. Antes que possa apreciar a paisagem com seus sentidos, ela deve ter sido formada na sua mente. As montanhas são camadas de pensamento e memórias assim como de minerais. (ARLANDER, 2003, tradução minha $)^{6}$

\footnotetext{
$\overline{4}$ "A Revolução Industrial introduziu outro efeito na paisagem sonora: a linha contínua (...) A linha achatada e contínua do som é uma construção artificial. Do mesmo modo que a linha reta no espaço, raramente ela é encontrada na natureza (...) Poucos anos atrás, enquanto ouvia o som dos martelos dos pedreiros no Takht-eJamshid no Teerã, compreendi subitamente que em todas as sociedades antigas a maior parte dos sons era separada e interrompida, enquanto hoje uma grande parte - talvez a maior - é contínua. Este novo fenômeno sonoro, introduzido pela Revolução Industrial e largamente ampliado pela Revolução Elétrica, sujeita-nos hoje a sons fundamentais permanentes e a faixas de ruído de amplo espectro que têm pouca personalidade ou senso de progressão" (SCHAFER, 2001, p. 116)

${ }^{5}$ No original: "The dream of 'healing wilderness' as salvation is just as culturally produced as any dream garden. And even those areas we think are free and untouched by culture are on closer examination actually being created, supported or protected by it. The wilderness does not name or locate itself. The sanctity of nature is of man." ${ }^{6}$ No original: "Even if we are taught that nature and human perception are of twodifferent worlds they are nevertheless inseparable. Before you canenjoy the landscape with your senses it must have been formed inyour mind. The mountains are layers of mind and memories as well as of minerals."
} 
Nessa perspectiva, percebe-se a intrínseca relação entre indivíduo e paisagem. Soundscape (paisagem sonora) é uma derivação da palavra landscape (paisagem). Ao vivenciar a paisagem das montanhas não vemos apenas o sol se pondo atrás do contorno das rochas, ou picos rochosos cobertos de neve, mas também sentimos o calor do sol, o frio da neve, o cheiro de umidade, o toque e a variação das rajadas de vento. A paisagem implica os sentidos, a memória, a sociedade. Por essa abordagem percebemos como a ideia de paisagem sonora, ao tratar o som como elemento independente e dissociável dos outros sentidos na percepção da experiência pode levantar outros questionamentos. É possível sentir o som do vento nos picos de neve sem sentir o frio? O canto do mesmo pássaro nas montanhas ou no litoral, ainda o faz o mesmo canto? Em um artigo essencial para pensar o desenvolvimento do conceito de soundscape intitulado Against Soundscape e publicado em 2007, Tim Ingold afirma que:

\begin{abstract}
O poder do conceito prototípico de paisagem repousa precisamente no fato de não estar vinculado a qualquer registro sensorial específico - seja de visão, audição, tato, paladar ou olfato. Na prática perceptual ordinária estes registro cooperam tão proximamente, e com tal sobreposição de função, que suas respectivas contribuições são impossíveis de serem separadas (INGOLD, 2015a)
\end{abstract}

Ingold levanta a questão de que o conceito de soundscape pode nos afastar do som em si e nos levar a um lugar semelhante ao que estão os estudos da cultura visual. Segundo ele, existe um pressuposto nos estudos da cultura visual que o poder da visão está nas imagens e, assim, esquece-se de pensar a luz em si. Para Ingold é importante não cair na armadilha de que o poder do som está na reprodução dos objetos sonoros, "(..) os ouvidos, assim como os olhos, são órgãos de observação, e não instrumentos de reprodução. Assim como usamos nossos olhos para ver e olhar, também usamos nossos ouvidos para ouvir conforme avançamos no mundo", dessa forma, "é à luz, e não à visão, que o som deveria ser comparado" (INGOLD, 2015a). Ingold fala sobre a necessidade de abandonarmos o conceito de soundscape, visto que:

Quando olhamos em volta em um dia bonito, nós vemos uma paisagem (landscape) banhada em luz do sol, e não uma paisagem luminosa (lightscape). Da mesma forma, ao ouvir nossos arredores, não ouvimos uma paisagem sonora (soundscape). Porque o som, eu argumentaria, não é o objeto mas o meio da nossa percepção. É no que ouvimos. Semelhantemente, nós não vemos a luz mas vemos nela. (INGOLD, 2015a)

Assim, Ingold insiste no rompimento da lógica que implica em um sujeito receptivo que percebe os objetos sonoros produzidos em uma realidade concreta, destacando que o som não é objeto mas meio da percepção. Para ele, luz e som são "infusões do meio" e, sendo assim, os estudos da luz e do som deveriam refletir sobre os fluxos do meio, em vez de se concentrar na superfície. 
(...) os estudiosos têm-se centrado na fixidez da conformação superficial, em vez de nos fluxos do meio. Eles têm, em outras palavras, imaginado um mundo de pessoas e objetos que já se tenham precipitado, ou solidificado, destes fluxos. Prosseguindo no equacionamento da solidez das coisas com a sua materialidade, eles planejaram a desmaterialização do meio no qual estão primordialmente imersos. Mesmo o ar que respiramos, e do qual a vida depende, torna-se um produto da imaginação (INGOLD, 2015a)

Em artigo intitulado Materials against materiality, publicado em 2007, Ingold apresenta um breve histórico do estudo da materialidade na antropologia e na arqueologia, afirmando que obras como The Mental and the Material, de Maurice Godelier (1986); Mind, Materiality and History, de Christina Toren (1999); Matter, Materiality and Modern Culture, editado por Paul Graves-Brown (2000) e Thinking Through Material Culture, de Karl Knappett (2005), apesar de tratarem explicitamente da materialidade e da cultura material, não tem quase nada a dizer sobre os materiais. Em vez de seguir certa tradição acadêmica que nos impele a falar não da materialidade dos materiais e de suas propriedades mas da materialidade dos objetos, Ingold propõe que nos aproximemos do material para pensar a materialidade. Segundo ele, essa análise abstrata das coisas já feitas em vez do contato com o material pode nos colocar em uma posição de mentes sem corpo em contato com um mundo material em vez de corpos de carne e osso em contato corpóreo com materiais de diversos tipos, fazendo com que a materialidade contribua, na verdade, para a desmaterialização do meio (INGOLD, 2015b). Ingold vê no trabalho de James Gibson em The ecological approach to visual perception (1979) uma alternativa aos estudos dos materiais e da materialidade onde ele distingue meio, substância e superfícies.

Para os seres humanos o meio é normalmente o ar. E claro que precisamos de ar para respirar. Mas além disso, oferecendo pouca resistência, ele permite-nos mover-nos - fazer coisas, produzir coisas e tocar coisas. Também transmite energia radiante e vibração mecânica, de modo que podemos ver e ouvir. E permite-nos cheirar, uma vez que as moléculas que estimulam os nossos receptores olfativos são difundidas nele. Assim o meio, de acordo com Gibson, proporciona movimento e percepção. Substâncias, por outro lado, são relativamente resistentes a ambos. Elas incluem todos os tipos de coisas mais ou menos sólidas como rochas, cascalho, areia, terra, barro, madeira, concreto e assim por diante. Tais materiais fornecem os fundamentos físicos necessários para a vida - precisamos deles para nos apoiarmos - mas geralmente não é possível vermos ou nos movermos através deles. $\mathrm{Na}$ interface entre o meio e a substância estão as superfícies. Todas as superfícies, de acordo com Gibson, têm certas propriedades. Estas incluem uma disposição particular, relativamente persistente, um grau de resistência à deformação e à desintegração, uma forma distintiva e uma textura caracteristicamente não homogênea. Superfícies são onde a energia radiante é refletida ou absorvida, 
quando as vibrações são transmitidas para o meio, onde vaporização ou difusão no meio ocorre, e aquilo contra o que os nossos corpos tocam. No que concerne à percepção, as superfícies estão, portanto, "Onde a maior parte da ação acontece" (Gibson, 1979:23) (INGOLD, 2015b)

Seguindo a aproximação de Gibson acerca da materialidade e do meio, Ingold, em Against Soundscape, associa os fluxos do meio ao tempo (weather):

Ora, o termo mundano para o que eu chamei de fluxos do meio é tempo. Quando estamos - como se diz - "a céu aberto", o tempo não é um mero fantasma, a substância dos sonhos. É, ao contrário, fundamental para a percepção. Nós não o percebemos, nós percebemos nele (Ingold, 2005a). Nós não tocamos o vento, mas tocamos nele; nós não vemos a luz do sol, mas vemos nela; nós não ouvimos a chuva, mas ouvimos nela. Assim, vento, sol e chuva, experimentados como sensação, luz e som, são essenciais para as nossas capacidades, respectivamente de tocar, ver e ouvir (INGOLD, 2015a)

Ingold desenvolve a relação entre os fluxos do meio e o tempo em um ensaio chamado Landscape or weather-world. Ao pensar a materialidade e as superfícies com fluidez, Ingold nos reposiciona do lugar de observadores passivos de um mundo material já solidificado e apartado de nossos corpos para o lugar de participantes imersos em um mundo em constante formação. Para ele, "Participação não se opõe a observação, mas é uma condição para isso, assim como a luz é uma condição para se ver as coisas, som para ouvi-las, e a sensação para senti-las" (INGOLD, 2015c). Sendo assim, pessoas e paisagens são constituídas mutualmente, visto que as paisagens têm seus significados e aparências definidos em relação as pessoas enquanto as pessoas desenvolvem seus conhecimentos e identidades em relação a paisagem em que se encontram imersos. Ao dizer que certa tradição acadêmica dos estudos da materialidade corrobora a desmaterialização do meio, Ingold levanta a possibilidade de pensarmos o vento, a chuva, a luz do sol, como fluxos do meio e não pertencentes a um reino distinto e distante do mundo material. Ao pensar o meio como algo separado do mundo material, seria como pensar que "A água da chuva entra no mundo material apenas quando se acumula em poças no chão, e a neve somente quando se amontoa" (INGOLD, 2015c). Na realidade, segundo Ingold:

A paisagem ainda não se solidificou do meio. Ela está passando por uma formação contínua, acima de tudo graças a imersão de suas superfícies multifacetadas naqueles fluxos do meio que chamamos de tempo - na luz do sol, no vento e assim por diante. O chão não é a superfície da materialidade em si, mas uma composição texturizada de diversos materiais que crescem, depositam-se e se entrelaçam em uma ação recíproca e dinâmica através da interface permeável entre o meio e as substâncias com o qual ele mantém contato (INGOLD, 2015c)

\footnotetext{
${ }^{7}$ A palavra tempo (em itálico) é usada ao longo do artigo para se referir ao conjunto de fenômenos meteorológicos em uma determinada região e em um determinado período. Weather.
} 
Ao levantar suas objeções ao conceito de paisagem sonora e à conformação superficial das coisas (scaping of things), Ingold utiliza-se da ideia de Gibson onde essas superfícies são "interfaces entre um tipo de material e outro - por exemplo entre pedra e ar - não entre o que é material e o que não é" (INGOLD, 2015c). No entanto, Ingold propõe um olhar sob a atmosfera, não como o lugar onde ocorrem os fluxos do meio, mas como fluxo do meio em si, aproximando-se do pensamento do filósofo Arnold Berleant ${ }^{8}$ :

Ao invés de serem opostos, mar e terra, junto ao litoral que marca seu perpétuo diálogo, parecem ser engolidos na esfera maior de forças e relações que compreendem o mundo-tempo (weather-world), juntos subsumidos sob a grande cúpula do céu. E nesta cúpula, onde o sol brilha, as tempestades se enfurecem e o vento sopra - e não, como Gibson supôs, na superfície dos objetos sólidos e no chão sobre o repousam - que "toda ação acontece" (Gibson 1979:23). Perceber e agir no mundo-tempo é alinhar sua conduta aos movimentos celestiais do sol, da lua e das estrelas, às alternâncias rítmicas da noite e do dia e das estações do ano, à chuva e ao dia aberto, à luz do sol e à sombra. Porque o tempo engole a paisagem, assim como a visão das coisas é engolida pela experiência da luz, a audição das coisas pela experiência do som, e o tato das coisas pela experiência do sentir (INGOLD, 2015c)

Essa compreensão de tempo implica em uma relação entre som e luz, como fluxos do meio, de tal maneira que não é possível separá-los. Da mesma maneira, na experiência do mundo, nossos sentidos estão tão envolvidos um ao outro que não é possível dissociar a experiência de ver, do ouvir, do tocar.

\section{Annette Arlander e o observador participante}

Annette Arlander se coloca como uma artista pesquisadora, sendo uma das pioneiras da performance art e na pesquisa artística na Finlândia. Como continuação de sua tese de doutorado, Performance as space, que levantava questões acerca de espaço e lugar em uma perspectiva da pesquisa teatral em relação ao estudo da arte contemporânea, Arlander propõe o conceito de Performing Landscape. Em uma série de textos e obras ao longo de mais de dez anos, Arlander se questiona sobre a possibilidade de performar com a paisagem. Ao longo desses anos de pesquisa artística, produção textual e docência, Arlander desenvolve diversos projetos que se relacionam com a paisagem e a passagem do tempo, evidenciando as variações climáticas na Finlândia e na Europa. Animal Years foi um projeto que teve início em 2002 e término em 2014, e ocorreu praticamente todo na ilha Harakka, em Helsinki. A artista propõe seguir o calendário chinês, que tem um ciclo de 12 anos, pesquisando determinados lugares da ilha a cada ano e nomeando a experiência com os nomes dos animais do calendário. Entre 2007 e 2008, Year of the Pig, Arlander propõe algumas ações que são registradas em vídeo e apontam

\footnotetext{
8 "Berleant, também, aponta seu olhar do oceano em direção a terra, e percebe não apenas que a terra passa por uma mudança contínua - 'devagar, com certeza, mas ainda assim incessante' - mas também que a fluidez não termina por aí. 'A atmosfera é ela mesma um meio fluido' (Berleant 2010: 139)” (INGOLD,2015c) 
questionamentos em como performar uma paisagem. Todas essas ações pressupõe repetições e a relação entre passagem do tempo, paisagem e variações no tempo.

Year of the Pig - Sitting on the Cliff I-II

"Envolvida em um cachecol cinza, sento no penhasco na costa noroeste da ilha Harakka por volta de uma vez por semana entre 6 de janeiro de 2007 e 3 de fevereiro de 2008. Na parte I, me viro para o sul e olho para o mar; na parte 2, me viro para o norte e olho em direção a cidade."

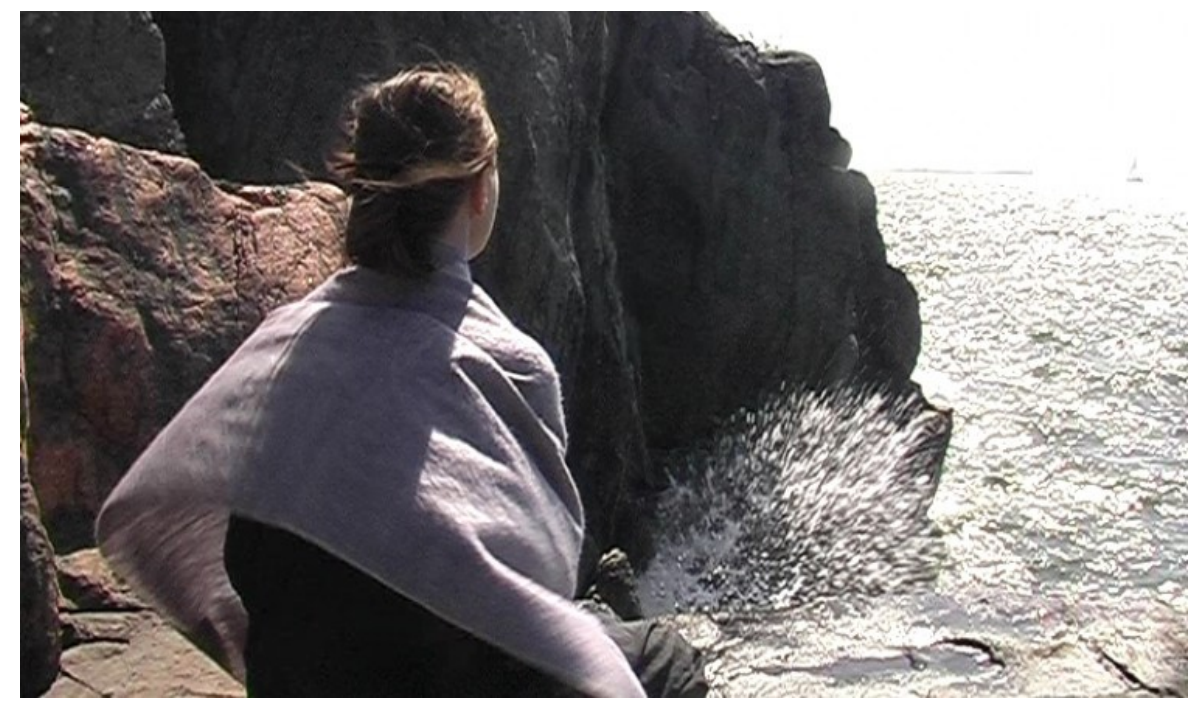

Year of the Pig - Weather Vane I

"Um cachecol por cima dos meus ombros, eu giro contra o horizonte da cidade nos penhascos ao noroeste da llha Harakka por volta de uma vez por semana entre 6 de janeiro de 2007 e 3 de fevereiro de 2008."

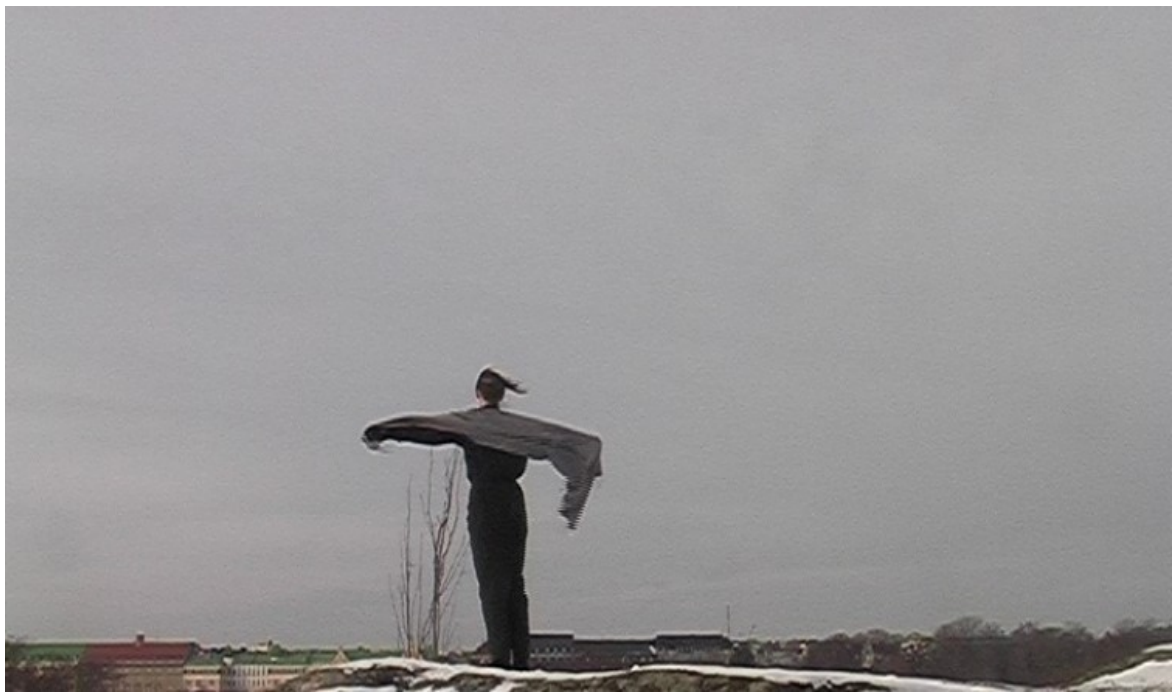


Arlander pôde presenciar as variações de vento, as diferentes intensidades da luz do sol, a neve se acumular no topo das pedras e derreter com a passagem da estação. Apesar da relação evidente entre as mudanças climáticas e o passar do ano, a potência da pesquisa de Arlander reside no fato de que sua ação compreende o corpo do artista pesquisador tragado, em movimento recíproco, pela paisagem, pelo lugar que escolhe para executar a ação. Chamo a atenção para a ação em Weather Vane I. Ao girar no mesmo ponto, uma vez por semana durante o ano todo, Arlander experimenta um modo de estar junto a performatividade da paisagem através de sua proposição performativa. Em sua relação com o vento, segundo Ingold, a performer não ouve o vento, mas ouve no vento, da mesma forma que não toca o vento, mas toca no vento. A audição no vento é tragada pela experiência do som, enquanto o tato no vento é tragado pela experiência do toque. Sendo assim, a performance de Arlander evidencia o tempo, os fluxos do meio, e coloca o corpo em vibração com a paisagem. Através da repetição, a artista propõe certa sintonia com os elementos do tempo onde, mesmo que apenas sentada em um penhasco, coloca-se em posição de observador e participante. Como vimos, para Ingold, a participação é uma condição para a observação, assim como o som é condição para ouvirmos e o toque é condição para o tato. Assim, girar o corpo em torno de si repetidamente a coloca em condição de observadora/participante de forma que o som do vento, o toque do vento no corpo, o cheiro do lugar, as cores que se embaralham nos olhos que giram, o movimento do cachecol, os pés na pedra, toda experiência se trata de corpo/paisagem, de performar junto a paisagem. Não é um corpo que percebe a paisagem sonora (soundscape), a paisagem luminosa (lightscape) e a paisagem tátil (touchscape) em sentidos distintos, mas como a experiência difusa da paisagem (landscape), justamente pela inespecificidade do sentido perceptivo que é atrelado ao conceito.

\section{Uma outra aproximação sonora}

Partindo dos pontos levantados por Ingold em sua discussão sobre a paisagem sonora, a experiência de Arlander junto a performatividade da paisagem trata de perceber e evidenciar a relação de observador sempre participante, imerso nos fluxos do meio. Se colocando no lugar de artista pesquisadora, Arlander produz muitos textos e documentos de seu processo criativo. Através da documentação e da reflexão sobre esses trabalhos, a artista pesquisadora faz apontamentos e sugere caminhos para um processo investigativo da paisagem. Ao se perguntar constantemente sobre as possibilidades da relação entre performance e paisagem, Arlander não busca definir um conceito fechado para performing landscape mas uma provocação constante que implica pensar o corpo, o observador participante, sempre na paisagem. Através dessa provocação e pelo tensionamento do conceito de paisagem sonora, é possível apontar caminhos para uma pesquisa artística/performativa do som que compreenda os elementos sonoros da paisagem não como objetos separados do observador, mas na perspectiva de que os sentidos cooperam imersos nos fluxos do meio. Quando estamos em um lugar elevado, a constante presença do vento é marcante tanto pelo som, que parece nos golpear os ouvidos, quanto pelo toque constante na pele, o esvoaçar dos cabelos e a 
resistência ao caminhar. Pensar que todos esses aspectos também são parte da paisagem sonora pode oferecer pistas de como, por exemplo, se aproximar do som do vento nas montanhas.

Uma forma comum de se aproximar da paisagem sonora das montanhas, por exemplo, é através da análise dos elementos sonoros presentes em uma gravação. Como um primeiro gesto investigativo, poderíamos captar inúmeras horas de arquivos de áudio, com microfones e configurações diversas, em diferentes montanhas ao redor do mundo, com o objetivo de pensar os elementos que constituem tal "paisagem sonora das montanhas". Apesar da captação de som feita in loco, não é incomum nos depararmos com trabalhos no campo das artes que são desenvolvidos quase que exclusivamente com base na manipulação desse material em uma ilha de edição. Certamente a captação de som através de gravadores e microfones é uma abordagem investigativa valiosa na pesquisa sonora. No entanto, se for tratada como único recurso de pesquisa, pode reforçar a relação onde o sujeito receptivo é separado da realidade concreta, limitando outros tantos possíveis desdobramentos. Além da captação de som, outras ações são possíveis e necessárias para um maior tensionamento do conceito de paisagem sonora e de suas implicações na prática de pesquisa. Tomo como exemplo o vento nas montanhas. Ouvindo diferentes trechos da gravação de som feita em uma montanha é possível identificar inúmeras variações, nuances, momentos delicados e momentos onde a intensidade do sopro do vento muda bruscamente. Podemos perceber a força e a modulação do vento conforme as rajadas golpeiam o microfone. Contudo, na ilha de edição, podemos apenas imaginar o frio cortante ao sentir o vento gelado contra a pele a cinco mil metros de altitude, ou esse mesmo ar golpeando os cabelos e entrando pelas narinas. A presença do corpo e do vento na paisagem, simultaneamente, carrega potências, estímulos, possibilidades de percepção e interação com o ambiente.

Ao desconsiderar a presença do corpo no espaço no processo de pesquisa sonora em artes, podemos restringir o som ao seu caráter de objeto sonoro, descartando a força que reside na cooperação dos sentidos na experiência perceptiva. Tim Ingold diz que "Vento e respiração estão intimamente relacionados no contínuo movimento de inspiração e expiração, que é fundamental à vida e ao ser. A inspiração é o vento se tornando a respiração, a expiração é a respiração se tornando vento" (INGOLD, 2015). Em uma breve reflexão em uma conferência de antropologia sobre "Vento, Vida e Saúde" (LOW \& HSU, 2008), essa discussão foi levantada, com a ideia de que o vento é corporificado (embodied) à constituição das pessoas que são afetadas por ele. Ingold disse se sentir desconfortável com essa afirmação:

(...) fez a respiração parecer um processo de coagulação, no qual o ar era de alguma forma sedimentado no corpo quando se solidifica. Reconhecendo que o corpo vivo, quando respira, é necessariamente varrido pelas correntes do meio, sugeri que o vento não é tanto corporificado quanto o corpo ventilado (Ingold, 2007b: S32). Parece-me, aliás, que o que se aplica ao vento também se aplica ao som. Afinal, o vento assobia, e as pessoas sibilam ou murmuram quando respiram. 
O som, assim como a respiração, é experimentado como um movimento de ir e vir, inspiração e expiração. Se é assim, então deveríamos dizer do corpo, quando canta, sibila, assobia ou fala, que é sonorizado. É como zarpar, lançando o corpo ao som como um barco sobre as ondas, ou, talvez mais apropriadamente, como uma pipa no céu (INGOLD, 2015)

Instigado pelas objeções de Tim Ingold ao conceito de paisagem sonora, volto minha atenção para suas observações a respeito dos fluxos do meio, ou seja, ao tempo, às forças meteorológicas. Sua análise do vento e, particularmente, a analogia que faz entre o ouvir e o ato de empinar uma pipa, me instigaram a buscar outras formas de me aproximar do vento na pesquisa sonora. Em um gesto motivado pela vontade de expandir as possibilidades de relação sonora com o vento, me propus a retomar o hábito praticado na infância. Comprei algumas pipas de um vendedor local, assim como fiz algumas em casa, para empinar em diferentes lugares de Fortaleza. Nessa ação investigativa, pude me atentar às variações de intensidade e direção do vento, ao senti-lo com as mãos e tateá-lo com os olhos. Ao me atentar a observação de Ingold quanto a cooperação dos sentidos imersos nos fluxos do meio, me propus nesse momento da prática de pesquisa a não fazer gravações de campo. Me concentro em sentir a intensidade, a direção e os redemoinhos do vento com as mãos, os olhos, o toque na pele, a temperatura, a luz do sol. Me abro a possibilidade de sentir no vento, sendo aqui o sentir um processo de "escuta atenta", a escuta de corpo todo em oposição à "audição passiva", onde todos os sentidos operam juntos nas forças geofísicas e meteorológicas.

Em uma preparação a essas visitas, quando se pensa o lugar e a pipa que será empinada, muitos fatores são levados em consideração. Se a pipa for empinada nas areias da Praia de Iracema, onde o vento é intenso e constante, a construção e a forma de manusear a pipa se diferenciam se for empinada em um lugar onde o vento não seja tão forte, como no Parque do Cocó. A temperatura também é fator importante na escolha do lugar, visto que em um lugar aberto como a praia preciso ficar a maior parte do tempo exposto ao sol enquanto em um parque posso me abrigar embaixo de uma árvore. A cada experiência pode-se apreender do espaço um novo conjunto de relações proporcionados pelo tempo. Esse simples processo evidenciou a mim a complexidade de relações que influenciam a percepção auditiva quando pensada em seu caráter multissensorial. Como sons semelhantes, como o canto de um mesmo pássaro ou uma mesma buzina de carro, podem ser percebidos de formas diferentes quando inúmeros fatores são alterados.

Em outro momento, durante o processo de pesquisa da obra Subida à $\mathrm{Pe}$ dra do Cruzeiro (2016), exposta no 670 Salão de Abril em Fortaleza, também busquei incorporar uma abordagem multissensorial ao me aproximar da paisagem. Nesse processo fiz algumas viagens à cidade de Quixadá, no interior do Ceará. Além de gravações de campo em alguns pontos da cidade, fiz diversos percursos a pé pelos mesmos lugares em diferentes momentos do dia. Nessas caminhadas, sem o uso de nenhum equipamento de captação de som ou imagem, buscava encontrar locais e momentos que me chamassem a atenção por algum som específico na paisagem. Por ser uma cidade repleta de monólitos, andei várias vezes sob essas rochas gigantescas, pude tocá-las e sentir a variação da intensidade do vento 
conforme subia ou descia por suas trilhas. Também sentia o som dos carros passando, das conversas nas casas, das televisões ligadas e das crianças brincando na rua diminuindo conforme me distanciava delas em direção ao topo das rochas. Lembro-me que ao longo de uma dessas trilhas, ao subir a Pedra do Cruzeiro que fica no centro da cidade, percebia o som da vizinhança se distanciando enquanto a intensidade do ruído do vento e de seu toque na pele aumentavam. Também me lembro de postes de eletricidade fincados nos monólitos durante todo o caminho, até alcançar o topo, onde há uma pequena estação elétrica. Essas impressões, essas experiências vivenciadas na paisagem, no vento, na luz do sol, em todos seus aspectos sensoriais, contribuíram para que eu pudesse desenvolver a escultura sonora.

Nesses exercícios de escuta expandida, onde compreende-se o processo de escuta através da cooperação dos sentidos imersos nos fluxos do meio em uma paisagem que não se resume ao seu caráter auditivo, me atentei para o fato de que, ao problematizar o conceito de paisagem sonora proposto por R. Murray Schaffer e refletir sobre as considerações de Tim Ingold, minhas práticas de pesquisa também foram revistas. Lançar-se ao som através da presença na paisagem, deixar-se sonorizar pelo ambiente, é uma possibilidade diante do tensionamento do conceito de paisagem sonora proposto por Ingold:

Finalmente, se o som é como o vento, então não vai ficar parado, tampouco colocar pessoas ou coisas em seu lugar. $\mathrm{O}$ som flui, como o vento sopra, por caminhos sinuosos, irregulares, e os lugares que descreve são como turbilhões, formados por um movimento circular em torno, em vez de uma localização física dentro. Seguir o som, isto é, ouvir é vagar pelos mesmos caminhos. A escuta atenta, em oposição à audição passiva, certamente implica o oposto do posicionamento (emplacement). Novamente, a analogia com empinar uma pipa é pertinente. Embora os pés de quem empina uma pipa possam estar firmemente plantados no local, não é o vento que os mantêm aí. Da mesma forma, a varredura do som continuamente se esforça em arrebatar os ouvintes, fazendo-os renderem-se ao seu movimento. É necessário um esforço para se ficar no lugar. E este esforço puxa contra o som ao invés de harmonizar-se com ele. O confinamento, em suma, é uma forma de surdez (INGOLD, 2015a)

Deslocar-se, vagar, experimentar e percorrer paisagens, sob essa perspectiva, podem ser atributos do ouvir, e abrem margem para a pesquisa de som em artes através de deslocamentos investigativos e proposições performáticas, trazendo questionamentos que colocam o artista como pesquisador e observador participante da paisagem. Talvez empinar uma pipa no topo de uma montanha, nos fale do som tanto quanto os golpes furiosos do vento contra um microfone.

\section{Referências}

ARLANDER, Annette. How to perform landscape? In: Performing landscape: notes on site-specific work and artistic research (texts 2001-2011). Helsinki. Theatre Academy Helsinki, 2012. 
ARLANDER, Annette. Moved by the wind. Performance Research. <http://www.performance-research.org >. Volume 8, No 4, 2003.

INGOLD, Tim. Quatro objeções ao conceito de paisagem sonora. In: Estar vivo: ensaios sobre movimento, conhecimento e descrição. Petrópolis, Vozes, 2015a.

INGOLD, Tim. Materiais contra materialidade. In: Estar vivo: ensaios sobre movimento, conhecimento e descrição. Petrópolis, Vozes, 2015b.

INGOLD, Tim. Paisagem ou mundo-tempo?. In: Estar vivo: ensaios sobre movimento, conhecimento e descrição. Petrópolis, Vozes, 2015c.

LOW, Chris \& HSU, Elisabeth. Wind, Life, Health: Anthropological and Historical Perspectives. Londres, Blackwell Publishing, 2008.

SCHAFER, R. Murray. (1977). A afinação do mundo. São Paulo, Editora da UNESP, 1997.

SCHAEFFER, Pierre. (1966). Tratado dos objetos musicais. Brasília, EdUnB, 1993.

THOMPSON, Emily. The soundscape of modernity: architectural acoustics and the culture of listening in america, 1900 - 1933. Cambridge. MIT Press, 2002.

TRUAX, Barry. (1978). Handbook for acoustic ecology. <http://www.sfu.ca/sonic-studio/handbook/> Acesso em 25 de novembro de 2016.

Recebido em 23/11/2016 Aprovado em 22/07/2017 